\title{
Interaction of Guanidine-type Surfactants with Biological Substances
}

\author{
Miyuki Miyake ${ }^{1 *}$, Takashi Nishikawa ${ }^{2}$ and Masahiko $\mathrm{Abe}^{3}$ \\ ${ }_{1}^{1}$ Functional Materials Research Laboratory, Lion Corporation (2-1, Hirai 7-chome, Edogawa-ku, Tokyo 132-0035, JAPAN) \\ ${ }^{2}$ Human \& Environmental Safety Evaluation Center, Lion Corporation (100 Tajima, Odawara, Kanagawa 256-0811, JAPAN) \\ ${ }^{3}$ Deptment of Industrial Chemistry, Faculty Science and Technology, Science University of Tokyo (2641, Yamazaki, Noda, Chiba 278-8510, JAPAN)
}

\begin{abstract}
The interaction of guanidine-type cationic surfactants with bovine serum albumin (BSA) and liposome were investigated. Dodecylguanidine hydrochloride $\left(\mathrm{C}_{12} \mathrm{~A}_{0} G\right)$ and several dodecanoylamide alkylguanidine hydrochlorides $\left(C_{12} A_{m} G, m=2,3,4,6\right)$ were used as the guanidine-type surfactants. In the interaction of these surfactants with BSA as a model protein, the binding isotherms of the surfactants to BSA were analysed. The structural change of the protein was also examined on the basis of circular dichroism and UV absobance data. In the interaction of these surfactants with liposome as a lipid bilayer model, we studied the effects of the surfactants on the solubilisation of liposomes and the release of carboxyfluorescein from liposomes. In addition, the effect of the surfactant molecular structure on the skin irritation was evaluated in connection with the interactions of the surfactants with BSA and liposome. It was found that small amounts of binding of $\mathrm{C}_{12} \mathrm{~A}_{0} \mathrm{G}$ caused both a partial destruction of a-helix and an aggregation of BSA. $C_{12} A_{0} G$ also induced the aggregation of liposomes, whereas $C_{12} A_{m} G$ showed no such action. The presence of $A_{m}$ group in $C_{12} A_{m} G$ appeared to reduce the skin irritation in parallel with the weakening of the interaction of the guanidine group with the protein and the lipid bilayer.
\end{abstract}

Key words: guanidine-type surfactant, BSA, lipid bilayer, binding isotherm, skin irritation

\section{INTRODUCTION}

Amino acid-type surfactants are widely used in the field of cosmetics because of their unique surface activity not exhibited by any common ionic surfactant ${ }^{1-3)}$. Among many amino acid-type surfactants, cationic lauroylamidebutylguanidine acetate (LAG), which adsorbs well to hair, has been developed and applied in hair conditioners ${ }^{4,5}$.

Guanidine groups interact strongly with biological substances ${ }^{6,7}$, and guanidine hydrochloride salts have been reported to be highly irritative ${ }^{8)}$. Addition of alkyl group to guanidine group strengthens their physiological activity"). Dodecylguanidine acetate salt has been used as an antibacterial agent for plants ${ }^{10)}$, and $\mathrm{N}$-acylarginine ethylester acetate salts display antibacterial activity ${ }^{11}$. While guanidine groups strongly affect the physiological activity of surfactants, hair conditioner containing LAG has been found to be safe for human use ${ }^{4)}$. Therefore, it is important to elucidate the relationship between the molecular structure of LAG and its safety.

Previously, we investigated the relationship between the molecular structure of guanidine-type surfactants and their aggregation properties ${ }^{12,13}$. Dodecylguanidine hydrochloride $\left(\mathrm{C}_{12} \mathrm{~A}_{0} \mathrm{G}\right)$ easily forms micelles because hydrogen-bonding between the guanidine groups facilitates the self-assembly of the surfactant molecules in aqueous media. The spacer group between guanidine group and alkyl group of LAG was found to weaken hydrogen-bonding between guanidine groups of LAG. It has been also reported that $\mathrm{C}_{12} \mathrm{~A}_{0} \mathrm{G}$ causes polyglutamic acid to adopt an $\alpha$-helical structure at low concentrations, whereas the spacer group in $\mathrm{C}_{12} \mathrm{~A}_{\mathrm{m}} \mathrm{G}$ lowered the $\alpha$-helix forming ability ${ }^{14)}$. Although there are several reports regarding the spacer effect of guanidine-type surfactants as mentioned above, the role of the spacer group has not been analysed with respect to the effects on organised biological substances like lipid bilayers and protein molecules.

The present paper addresses the interaction of guanidine-type surfactants with bovine serum albumin (BSA) and liposomes as models of organised biological substances. We compare the interactions of these

* Correspondence to: Miyuki Miyake, Functional Materials Research Laboratory, Lion Corporation, 2-1, Hirai 7-chome, Edogawa-ku, Tokyo 132-0035, JAPAN

E-mail: miyamiyu@lion.co.jp

Accepted October 9, 2009 (received for review August 11, 2009)

Journal of Oleo Science ISSN 1345-8957 print / ISSN 1347-3352 online

http://www.jstage.jst.go.jp/browse/jos/ 
surfactants to those of DTAC and examine the relationship between the surfactant molecular structure and skin irritation.

\section{EXPERIMENTAL}

\subsection{Materials}

Guanidine-type surfactants were synthesised by reacting amines with cyanamide as reported earlier ${ }^{4}$. n-Dodecylamine and dodecanoylamide alkylamine, which were synthesised from methyl laurate and diaminoalkane, respectively, were reacted with cyanamide in the presence of acetic acid to yield $\mathrm{C}_{12} \mathrm{~A}_{0} \mathrm{G}$ and $\mathrm{C}_{12} \mathrm{~A}_{\mathrm{m}} \mathrm{G}(\mathrm{m}=2,3,4,6)$ as acetate salts. After purification, the acetate salts were decomposed with an equivalent amount of sodium pyrrolidone carboxylate (PCANa) dissolved in water at $60^{\circ} \mathrm{C}$, and the solution was cooled to form PCA salts deposits. The obtained PCA salts were re-dissolved in water at $60^{\circ} \mathrm{C}$, and an excess amount of $\mathrm{NaCl}$ and an equivalent amount of hydrochloric acid were added to the solution to salt out the hydrochloride salts. These salts were then recrystallised three times from acetone after removing the sodium chloride. The purity of the surfactant salts was determined to be $>99.5 \%$ by means of qualitative characterisation with ${ }^{1} \mathrm{HNMR}$ and TLC and quantitative analysis with HPLC and amine value determination. Figure 1 shows the chemical structures of the synthesised guanidine-type surfactants.

Bovine serum albumin (BSA) and egg yolk phosphatidylcholine were purchased from Sigma Co. and Asahi Kasei K.K, respectively. Carboxyfluorescein (CF) was obtained from Sigma Co.

\section{$\mathrm{C}_{11} \mathrm{H}_{23}-\mathrm{CNH}_{(}\left(\mathrm{CH}_{2}\right)_{m}-\mathrm{NH}-\mathrm{C}-\mathrm{NH}-\mathrm{HCl}$ O $\quad \mathbf{N H}_{2}$}

Dodecanoyl amidoalkylguanidine hydrochloride $\left(\mathrm{C}_{12} \mathrm{~A}_{\mathrm{m}} \mathrm{G}: \mathrm{m}=2,3,4,6\right)$

\section{$\mathrm{C}_{12} \mathrm{H}_{25}-\mathrm{NH}-\mathrm{C}-\mathrm{NH}-\mathrm{HCl}$ $\mathbf{N H}_{2}$}

Dodecylguanidine hydrochloride $\left(\mathrm{C}_{12} \mathrm{~A}_{0} \mathrm{G}\right)$

Fig. 1 Chemical Structures of $\mathrm{C}_{12} \mathrm{~A}_{\mathrm{m}} \mathrm{G}$ and $\mathrm{C}_{12} \mathrm{~A}_{0} \mathrm{G}$.

\subsection{Binding isotherm}

An aqueous solution of BSA and an aqueous solution of $\mathrm{C}_{12} \mathrm{~A}_{0} \mathrm{G}, \mathrm{C}_{12} \mathrm{~A}_{4} \mathrm{G}$ and DTAC were mixed to give desired concentrations for both components. The mixed solutions were left for $5 \mathrm{~h}$ at $25^{\circ} \mathrm{C}$ to reach binding equilibrium. The concentration of BSA in the mixed solutions was fixed at 9.0 $\times 10^{-6} \mathrm{M}$, and the concentrations of the cationic surfactants were varied in a range below their cmc in pure water ${ }^{12,13)}$, i.e., in a range up to $6 \mathrm{mM}$ for $\mathrm{C}_{12} \mathrm{~A}_{0} \mathrm{G}$ and $\mathrm{C}_{12} \mathrm{~A}_{4} \mathrm{G}$, and up to $16 \mathrm{mM}$ for DTAC. Each mixed solution was placed in a test tube equipped with a membrane filter (MW fractionation = 10000). The tubes were centrifuged at $5000 \mathrm{rpm}$ to separate the solution containing only surfactant monomers from the mixed solution. The surfactant monomer concentration was determined by separate-phase titration using SDS with dichlorofluorescein as an indicator.

\subsection{CD spectrum and UV difference spectrum}

The CD spectrum of the mixed solution of BSA and surfactants were measured by a Jasco J-500 CD spectrophotometer. It is known that the $\alpha$-helical structure of BSA shows a strong negative double minimum in the wavelength range of $200-230 \mathrm{~nm}$, and the negative ellipticity decreases with the addition of surfactants to BSA solution ${ }^{15}$. The change of the $\alpha$-helix content induced by the surfactant addition was evaluated by the molar ellipticity at $220 \mathrm{~nm},[\theta]_{220}$. The UV difference spectra for the surfactant-BSA mixed solutions were measured by a Hitachi 577 spectrophotometer. The samples employed for the spectroscopic measurements were the same as those used for binding isotherm experiments (2.2).

\subsection{Liposome preparation, solubilisation, and CF release}

An aqueous unilamellar vesicle suspension was prepared by the following way. A thin lipid film was formed on the surface of a flask by removing the solvent from an egg yolk phosphatidylcholine solution in chloroform. A tris-hydrochloric acid buffer solution (50 mM, pH 7.5) was added to the film, and the mixture was ultrasonically treated for $30 \mathrm{~min}$ at $35 \mathrm{~mW}$ to yield a suspension of small unilamellar vesicle (SUV). The size of the liposomes in the suspension ranged from 50 to $70 \mathrm{~nm}$. After surfactant solutions with given concentrations were added to the SUV suspension, the mixtures were incubated at $25^{\circ} \mathrm{C}$ for $2 \mathrm{~h}$ (the final lipid concentration was $1 \mathrm{mM}$ ). Then, the scattered light intensity at $400 \mathrm{~nm}, I$, for each mixture was measured using a Hitach 650-60 spectrofluorometer.

Solubilisation of liposome by surfactants was evaluated in terms of the relative scattered-light intensity expressed as

Relative scattered light intensity $(\%)=I / I_{0} \times 100$

where $I_{0}$ represents the scattered-light intensity for the surfactant-free SUV suspension.

$\mathrm{CF}$ containing liposomes were prepared in a similar way by using $\mathrm{CF}$-added tris-hydrochloric acid buffer and ultrasonic treatment. After gel filtration (Sephadex G-75) in tris-hydrochloric acid buffer (50 mM, pH 7.5) containing 160 $\mathrm{mM} \mathrm{NaCl}, 1 \mathrm{mM}$ SUV suspension containing $10 \mathrm{mM} \mathrm{CF}$ was prepared. Since CF forms ionic complexes with cationic surfactants, polyoxyethylene lauryl ether $(\mathrm{EO}=7$, NRE, Lion Chemical co., $0.01 \%$ ) and the guanidine-type surfactant 
of $0.002 \%$ were mixed with the SUV suspension, and the mixture was left for $30 \mathrm{~min}$ at $25^{\circ} \mathrm{C}$. The amount of $\mathrm{CF}$ released was determined at the excitation and fluorescence wavelengths of 492 and $520 \mathrm{~nm}$, respectively. The amount of $\mathrm{CF}$ released in the presence of $0.01 \mathrm{wt} \% \mathrm{NRE}$ was $57.9 \%$. The excess amount of $\mathrm{CF}$ release caused by the mixing of guanidine-type surfactants with NRE was evaluated.

\subsection{Continuous skin reaction test}

Skin reaction evaluations were performed using 5 Hartley line female guinea pigs ( 8 weeks old). Three sections $(2 \mathrm{~cm} \times 2 \mathrm{~cm})$ on each of both sides of the dehaired abdomen were used for skin testing. Solutions (3 $\mathrm{w} / \mathrm{v} \%, 0.03 \mathrm{ml})$ of the guanidine-type surfactants $\left(\mathrm{C}_{12} \mathrm{~A}_{0} \mathrm{G}\right.$ and $\left.\mathrm{C}_{12} \mathrm{~A}_{\mathrm{m}} \mathrm{G}, \mathrm{m}=2,3,4,6\right)$ and DTAC were applied to the test parts once a day for 15 days. Skin reactions were observed daily just before the next surfactant application for the 15 days. The observations were also made at 1, 2, 5, and 7 days after the last application (i.e., 15, 16, 19, and 21 days after the first application). Following the Draize method ${ }^{16)}$, each tested animal was given a skin reaction score that was the sum of scores for "erythema and eschar" and "edema" (Table 1). The mean score for the tested animals was calculated daily using Eq. 2.

Skin reaction score $=$

$\mathrm{S}$ (erythema + edema) scores/number of animals (5) (2)

This test was based on the method described in the Guide Book for Marketing and Manufacturing of Cosmetics and Quasi-drugs ${ }^{17}$.

\section{RESULTS AND DISCUSSION}

\subsection{Binding of guanidine-type surfactants to BSA}

The binding of guanidine-type surfactants to protein was evaluated using BSA as a model protein. The binding behaviours were compared among the guanidine-type surfactants $\mathrm{C}_{12} \mathrm{~A}_{0} \mathrm{G}, \mathrm{C}_{12} \mathrm{~A}_{4} \mathrm{G}$ (a representative of $\mathrm{C}_{12} \mathrm{~A}_{\mathrm{m}} \mathrm{G}$ ), and DTAC (a common cationic surfactant). Figure 2 shows the binding isotherms of the three surfactant species at $25^{\circ} \mathrm{C}$.
It can be seen in Fig. 2 that the binding behaviour depends strongly on the surfactant concentration region. In the low concentration range (region I in Fig. 2), the amount of bound surfactant increases gently with the increase in the surfactant concentration, while in high concentration range (region II in Fig. 2) it increase steeply. As for the surfactant binding to BSA, it has been reported that the binding in low surfactant concentration range takes place with no significant change in the protein structure, while the binding in high surfactant concentration range causes the change in secondary structure of the protein ${ }^{18}$. As is demonstrated by $\mathrm{CD}$ spectral data shown later, the region I in Fig. 2 corresponds to the former and the region II to the later. It should be noted here that in the case of guanidine-type surfactants, the deposition of the surfactant-protein complexes was observed in the concentration range starting from the vicinity of binding saturation in the region I and extending to the region II (shaded area in Fig. 2). $\mathrm{C}_{12} \mathrm{~A}_{0} \mathrm{G}$ showed a stronger tendency for the complex deposition than $\mathrm{C}_{12} \mathrm{~A}_{4} \mathrm{G}$. The complexes dissolve again in region II when the amount of bound surfactant becomes large.

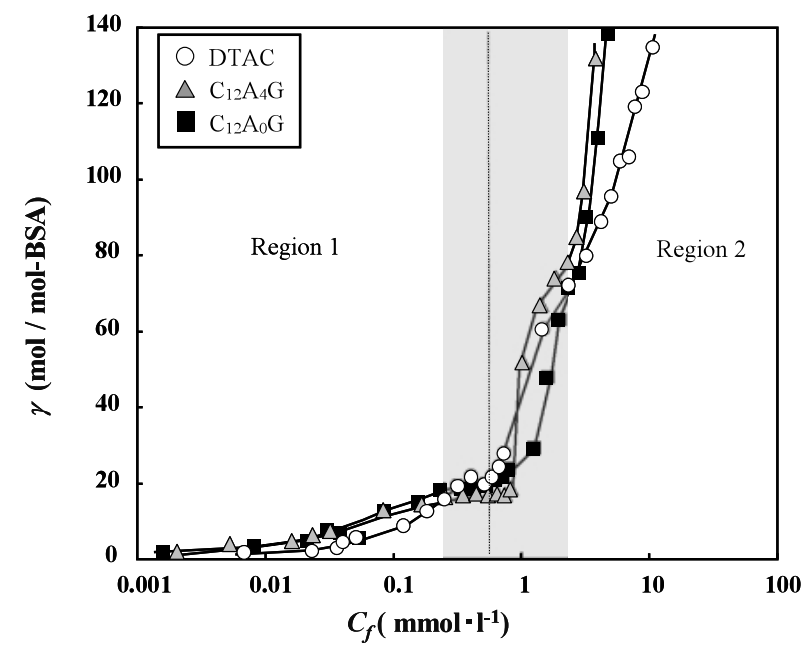

Fig. 2 Binding Isotherms of DTAC, $\mathrm{C}_{12} \mathrm{~A}_{0} \mathrm{G}$ and $\mathrm{C}_{12} \mathrm{~A}_{4} \mathrm{G}$. to BSA at $25^{\circ} \mathrm{C}$.

(Gray zone is the complex deposition region of $\mathrm{C}_{12} \mathrm{~A}_{0} \mathrm{G}$ and $\left.\mathrm{C}_{12} \mathrm{~A}_{4} \mathrm{G}\right)$

Table 1 Evaluation of Skin Reaction (Draize method).

\begin{tabular}{ll}
\hline Erythema and Eschar Formation & Edema Formation \\
\hline 0: No erythema & 0: No edema \\
1: Very slight erythema (barely perceptible) & 1: Very slight edema (barely perceptible) \\
2: Well defined erythema & 2: Slight edema (edges of area well defined by definite raising) \\
3: Moderate to severe erythema & 3: Moderate edema (raised approximately $1 \mathrm{~mm}$ ) \\
4: Severe erythema (beetredness) to slight eschar & 4: Severe edema (raised more thean $1 \mathrm{~mm}$ and extending \\
$\quad$ formation (injuries in depth) & beyond area of exposure) \\
\hline
\end{tabular}


The guanidine-type surfactants $\mathrm{C}_{12} \mathrm{~A}_{0} \mathrm{G}$ and $\mathrm{C}_{12} \mathrm{~A}_{4} \mathrm{G}$ begin to bind to BSA at lower concentrations than DTAC. The binding data in region I were analyzed applying the Scatchard plot ${ }^{19)}$ (Eq. 3),

$$
\gamma / C_{f}=n K-K \gamma
$$

where $\gamma$ is the amount of bound surfactant ( $\mathrm{mol} / \mathrm{mol}-\mathrm{BSA}$ ), $C_{f}$ is the surfactant concentration in the bulk solution, $K$ is the binding constant and $n$ is the number of binding sites. Figure 3 shows the Scatchard plots for the three cationic surfactants at $25^{\circ} \mathrm{C}$.

All the surfactants examined here provide binding curves composed of two straight lines. This means that

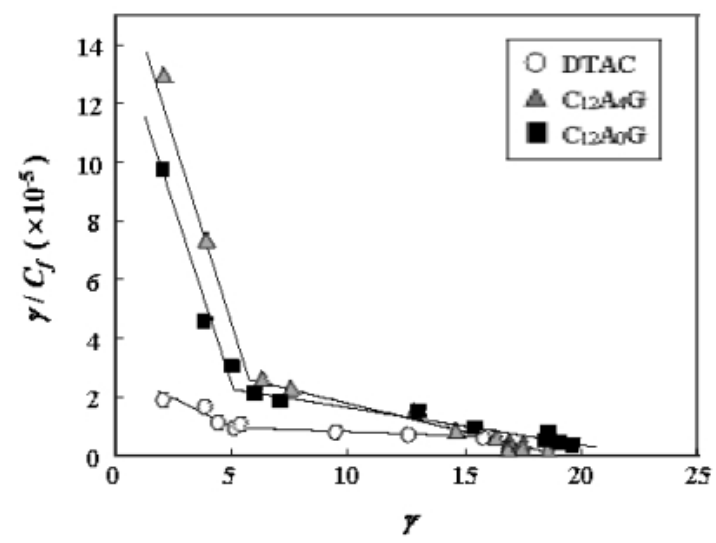

Fig. 3 Scatchard Plots for the Binding of DTAC, $\mathrm{C}_{12} \mathrm{~A}_{0} \mathrm{G}$ and $\mathrm{C}_{12} \mathrm{~A}_{4} \mathrm{G}$ to $\mathrm{BSA}$ at $25^{\circ} \mathrm{C}$. there are two steps for the binding of the surfactants to BSA in region I. Then, $\gamma$ is expressed by Eq. 4.

$$
\gamma=\gamma_{1}+\gamma_{2}=n_{1} K_{1} C_{f}\left(1+K_{1} C_{f}\right)^{-1}+n_{2} K_{2} C_{f}\left(1+K_{2} C_{f}\right)^{-1}
$$

where subscripts 1 and 2 refer to the parameters for the first and the second steps, respectively. The values of $K$ and $n$ in each step were determined from the straight lines in Fig. 3 using the modified expression of Eq. 4, and they are listed in Table 2. The values of $n$ obtained for DTAC, $\mathrm{C}_{12} \mathrm{~A}_{0} \mathrm{G}$, and $\mathrm{C}_{12} \mathrm{~A}_{4} \mathrm{G}$ ranged from 6 to 9 in the first step and from 13 to 24 in the second step. The $n$ value for the first step corresponds to that previously reported for cationic surfactants ${ }^{18)}$. The binding constants in the two steps for the guanidine-type surfactants are an order of magnitude larger than that for DTAC, indicating that the guanidine-type surfactants have a higher binding affinity.

Free energy changes associated with the binding were calculated using Eq. 5. The thermodynamic parameters of binding were then calculated from Eqs. 6 and 7 based on the free energy changes at $25^{\circ} \mathrm{C}$ and $35^{\circ} \mathrm{C}$. In Eq. 6, $T_{1}$ and $T_{2}$ are 298 and $308 \mathrm{~K}$, respectively, and $\Delta G_{T 1}$ and $\Delta G_{T 2}$ are the free energies of binding at respective temperatures.

$$
\begin{aligned}
& \Delta G=-R T \ln K \\
& \Delta G_{T 1} / T_{1}-\Delta G_{T 2} / T_{2}=-\Delta H\left(1 / T_{2}-1 / T_{1}\right) \\
& \Delta G=\Delta H-T \Delta S
\end{aligned}
$$

\begin{tabular}{|c|c|c|c|c|c|c|c|}
\hline & Step & $\begin{array}{c}\text { Temp } \\
(\mathrm{K})\end{array}$ & $\mathrm{n}$ & K & $\underset{(\mathrm{kJ} / \mathrm{mol})}{\Delta \mathrm{G}}$ & $\underset{(\mathrm{kJ} / \mathrm{mol})}{\Delta \mathrm{H}}$ & $\underset{(\mathrm{kJ} / \mathrm{mol})}{\mathrm{T} \Delta \mathrm{S}}$ \\
\hline \multirow{5}{*}{ DTAC } & \multirow{2}{*}{1} & 298 & 8.6 & $2.85 \times 10^{4}$ & -25.4 & \multirow{2}{*}{16.8} & \multirow{2}{*}{42.22} \\
\hline & & 308 & 8.0 & $3.55 \times 10^{4}$ & -26.8 & & \\
\hline & & & & & & & \\
\hline & \multirow{2}{*}{2} & 298 & 24.3 & $3.51 \times 10^{3}$ & -20.2 & \multirow{2}{*}{43.6} & \multirow{2}{*}{63.8} \\
\hline & & 308 & 20.1 & $6.21 \times 10^{3}$ & -22.4 & & \\
\hline \multirow{5}{*}{$\mathrm{C}_{12} \mathrm{~A}_{0} \mathrm{G}$} & \multirow{2}{*}{1} & 298 & 6.1 & $2.33 \times 10^{5}$ & -30.6 & \multirow{2}{*}{-25.0} & \multirow{2}{*}{5.6} \\
\hline & & 308 & 7.9 & $1.68 \times 10^{5}$ & -30.8 & & \\
\hline & & & & & & & \\
\hline & \multirow{2}{*}{2} & 298 & 17.5 & $1.21 \times 10^{4}$ & -23.3 & \multirow{2}{*}{-6.60} & \multirow{2}{*}{16.7} \\
\hline & & 308 & 16.8 & $1.11 \times 10^{4}$ & -23.9 & & \\
\hline \multirow{5}{*}{$\mathrm{C}_{12} \mathrm{~A}_{4} \mathrm{G}$} & \multirow{2}{*}{1} & 298 & 7.2 & $2.43 \times 10^{5}$ & -30.7 & \multirow{2}{*}{-32.8} & \multirow{2}{*}{-2.1} \\
\hline & & 308 & 6.6 & $1.58 \times 10^{5}$ & -30.7 & & \\
\hline & & & & & & & \\
\hline & \multirow{2}{*}{2} & 298 & 11.9 & $2.08 \times 10^{4}$ & -24.6 & \multirow{2}{*}{-42.5} & \multirow{2}{*}{-17.9} \\
\hline & & 308 & 13.4 & $1.19 \times 10^{4}$ & -24.0 & & \\
\hline
\end{tabular}

Thermodynamic parameters thus obtained are summarized in Table 2.

The values of $\Delta H$ and $\Delta S$ must contain rather large

Table 2 Thermodynamic Parameters for Binding of DTAC, $\mathrm{C}_{12} \mathrm{~A}_{0} \mathrm{G}$, and $\mathrm{C}_{12} \mathrm{~A}_{4} \mathrm{G}$. to BSA. 
errors, because they were derived from $\Delta G$ values at only two temperatures. Nevertheless, a qualitative discussion may be allowed as mentioned below. $\Delta H$ for binding of DTAC is positive, that is, the binding process is endothermic. This indicates that the binding of DTAC to BSA is driven by the hydrophobic interaction between the surfactant hydrocarbon chain and the hydrophobic binding site in the protein; the positive $\Delta H$ compensated by positive $\Delta S$ is characteristic of the hydrophobic effect. In contrast, $\Delta H$ obtained for binding for $\mathrm{C}_{12} \mathrm{~A}_{0} \mathrm{G}$ and $\mathrm{C}_{12} \mathrm{~A}_{4} \mathrm{G}$ are negative. This suggests that the hydrogen-bond interaction participates in the binding process of guanidine-type surfactants in addition to hydrophobic interaction; it is likely that hydrogen-bond is formed between the guanidine group and a certain side chain of amino acid residues near the binding site.

\subsection{Structural changes in BSA induced by guanidine-type surfactants and DTAC}

Figure 4 shows $[\theta]_{220}$ obtained for the surfactant-BSA mixed solution as a function of the surfactant concentration. The difference in absorbance at $288 \mathrm{~nm}$ is plotted in Fig. 5 as a function of the surfactant concentration.

With the addition of DTAC, the values of $[\theta]_{220}$ are kept at almost constant in region $\mathrm{I}$, indicating that DTAC molecules cause no significant change in $\alpha$-helix of BSA in corresponding concentration range. This is also the case up to about $3 \mathrm{mM}$ in region II. Further increase in DTAC concentration results in the decrease in $[\theta]_{220}$, which demonstrates the disruption of $\alpha$-helical structure. The change in UV absorption is also quite small in region I, although a slight red-shift is seen. In region II, the

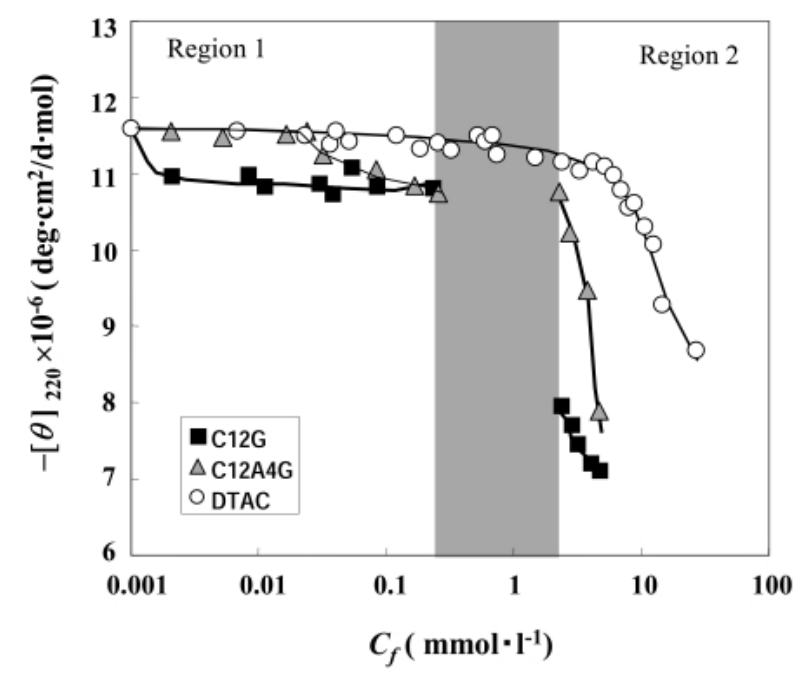

Fig. 4 Molar Ellipticity Obtained for BSA Solutions as a Function of Equilibrium Concentration of DTAC, $\mathrm{C}_{12} \mathrm{~A}_{0} \mathrm{G}$ and $\mathrm{C}_{12} \mathrm{~A}_{4} \mathrm{G}$ at $25^{\circ} \mathrm{C}$. (Gray zone is the complex deposition region of $\mathrm{C}_{12} \mathrm{~A}_{0} \mathrm{G}$ and $\mathrm{C}_{12} \mathrm{~A}_{4} \mathrm{G}$ )

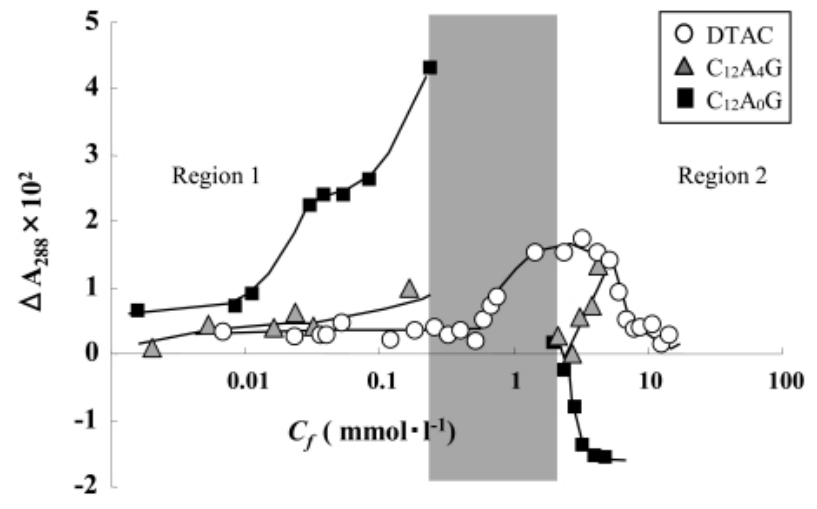

Fig. 5 Difference in Absorbance at $288 \mathrm{~nm}$ in the Presence and Absence of DTAC, $\mathrm{C}_{12} \mathrm{~A}_{0} \mathrm{G}$ and $\mathrm{C}_{12} \mathrm{~A}_{\mathrm{m}} \mathrm{G}$ at $25^{\circ} \mathrm{C}$. (Gray zone is the complex deposition region of $\mathrm{C}_{12} \mathrm{~A}_{0} \mathrm{G}$ and $\left.\mathrm{C}_{12} \mathrm{~A}_{4} \mathrm{G}\right)$

red-shift increases up to about $3 \mathrm{mM}$, and then it decreases with further increase in DTAC concentration. An appreciable red-shift in region II suggests that tyrosine and/or tryptophane residues are put into more hydrophobic environment compared with native BSA. This environmental change may be attributed to some structural change of the protein. Or, the hydrocarbon chains of bound DTAC might produce hydrophobic environment around the chromophores, since the binding number is significantly increased in region II.

The effects of guanidine-type surfactants on $[\theta]_{220}$ and $\Delta A_{288}$ is quite different from those of DTAC. $\mathrm{C}_{12} \mathrm{~A}_{0} \mathrm{G}$ molecules reduces $[\theta]_{220}$ appreciably at such low concentration as $C_{f}=0.002 \mathrm{mM}$. This shows that $\mathrm{C}_{12} \mathrm{~A}_{0} \mathrm{G}$ induces a partial destruction of $\alpha$-helix of BSA even at extremely low concentration. The depression of $[\theta]_{220}$ in region II is much greater for $\mathrm{C}_{12} \mathrm{~A}_{0} \mathrm{G}$ than for DTAC. Thus, disrupting action of $\mathrm{C}_{12} \mathrm{~A}_{0} \mathrm{G}$ on $\alpha$-helix is much stronger than that of DTAC. This strong action would be attributed to an intrinsic nature of $\mathrm{C}_{12} \mathrm{~A}_{0} \mathrm{G}$ originating from the presence of guanidine group, because the binding numbers at the concentration just after the deposition region of the surfactant-protein complex are comparable for $\mathrm{C}_{12} \mathrm{~A}_{0} \mathrm{G}$ and DTAC. The red-shift of UV absorption induced by $\mathrm{C}_{12} \mathrm{~A}_{0} \mathrm{G}$ in region $\mathrm{I}$ is also greater than that for the case of DTAC. Although $[\theta]_{220}$ remains unchanged in region $\mathrm{I}$, the red-shift increases rather steeply with the increase in $\mathrm{C}_{12} \mathrm{~A}_{0} \mathrm{G}$ concentration in this region, which suggests that the environment around the chromophore becomes more and more hydrophobic. Hydrocarbon chains of bound $\mathrm{C}_{12} \mathrm{~A}_{0} \mathrm{G}$ might bring about the hydrophobic environment around tyrosine and/or tryptophane residues in BSA. However, the reason for this red-shift of UV absorption occurring at low binding number without affecting $\alpha$-helical structure is unclear at the present time. UV absorption for $\mathrm{C}_{12} \mathrm{~A}_{0} \mathrm{G}$ system exhibits a blue-shift in region II. This can be 
understood as that the chromophores are exposed to hydrophilic environment due to a significant disruption of $\alpha$-helix followed by unfolding of the polypeptide chain.

The tendency of the change in $[\theta]_{220}$ and $\Delta A_{288}$ caused by $\mathrm{C}_{12} \mathrm{~A}_{4} \mathrm{G}$ is similar to the case of $\mathrm{C}_{12} \mathrm{~A}_{0} \mathrm{G}$, although the effect is much weaker for $\mathrm{C}_{12} \mathrm{~A}_{4} \mathrm{G}$. The difference in the effectiveness must be attributed to the presence of $A_{4}$ group which separate a hydrocarbon chain and guanidine group in the surfactant molecule. It is likely that the spacer group acts to inhibit the occurrence of the characteristic function of guanidine group when the surfactant is incorporated into some organized molecules or molecular assemblies like proteins and lipid bilayers. The characteristic function such as a strong hydrogen-bond forming ability would appear most effectively when the guanidine group is directly linked to hydrocarbon chain, because the anchoring by hydrocarbon chain would fix the guanidine group at the position convenient for, say, hydrogen-bond interaction.

\subsection{Solubilisation of liposomes and release of CF}

Figure 6 shows the change in scattered-light intensity caused by the addition of the surfactants to SUV suspension. The relative scattered-light intensity

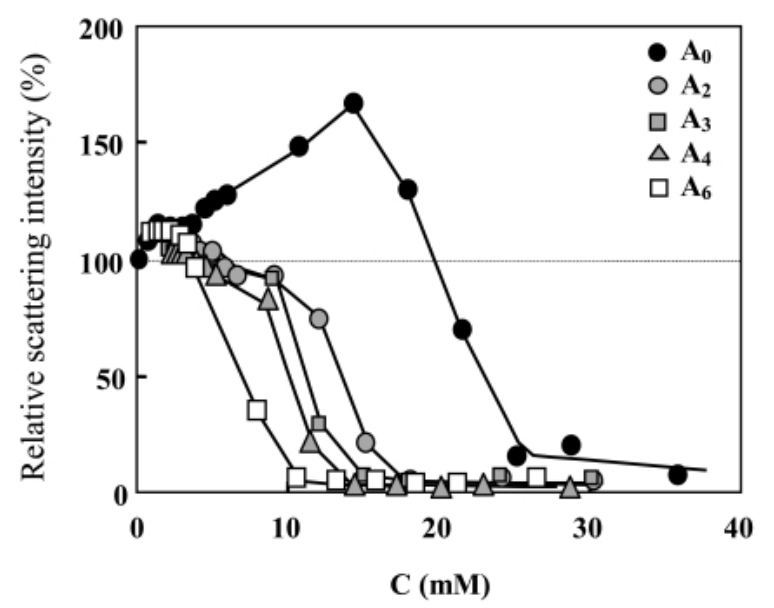

Fig. 6 Relative Scattered Light Intensity of Liposome Suspension as a Function of the Concentration of $\mathrm{C}_{12} \mathrm{~A}_{\mathrm{m}} \mathrm{G}$ and $\mathrm{C}_{12} \mathrm{~A}_{0} \mathrm{G}$. increases with $\mathrm{C}_{12} \mathrm{~A}_{0} \mathrm{G}$ concentration, suggesting that the liposome aggregation takes place in the presence of $\mathrm{C}_{12} \mathrm{~A}_{0} \mathrm{G}$. With further increase in the surfactant concentration, the relative scattered-light intensity starts to decrease around $15 \mathrm{mM}$ due to solubilisation of liposome by the surfactant. In the case of $\mathrm{C}_{12} \mathrm{~A}_{\mathrm{m}} \mathrm{G}$, the relative scattered-light intensity increases only slightly, and liposome solubilisation is observed at surfactant concentrations much lower than that for $\mathrm{C}_{12} \mathrm{~A}_{0} \mathrm{G}$. When the solubilising ability of the surfactants is compared in terms of their concentrations providing 50\% relative scattered-light intensity, the following decreasing order is observed: $A_{6}>A_{4}>A_{3}>A_{2}>>A_{0}$.

Figure 6 demonstrates a remarkable difference in the solubilization behavior between $\mathrm{C}_{12} \mathrm{~A}_{0} \mathrm{G}$ and $\mathrm{C}_{12} \mathrm{~A}_{\mathrm{m}} \mathrm{G}$; i.e., the spacer effect is clearly seen in the interaction of the surfactants with egg PC liposomes. $\mathrm{C}_{12} \mathrm{~A}_{0} \mathrm{G}$ induces the liposome aggregation before solubilization starts. This may be attributed to the strong hydrogen-bond forming tendency of guanidine group in $\mathrm{C}_{12} \mathrm{~A}_{0} \mathrm{G}$. When the surfactant is added to liposome suspension, the surfactant molecules are, at the first stage, incorporated into the lipid bilayer of liposome membrane. Then, there would appear liposomes with guanidine groups distributed on the outer surface. It is likely that the hydrogen-bonding between guanidine groups on neighbouring liposomes promotes the aggregation of the liposome. For $\mathrm{C}_{12} \mathrm{~A}_{\mathrm{m}} \mathrm{G}$, the liposome aggregation would be suppressed, because the presence of spacer group weakens hydrogen-bonding ability of guanidine group ${ }^{12,13}$. Anotherr remarkable difference between $\mathrm{C}_{12} \mathrm{~A}_{0} \mathrm{G}$ and $\mathrm{C}_{12} \mathrm{~A}_{\mathrm{m}} \mathrm{G}$ is that the surfactant concentration corresponding to the onset point of solubilization is extremely high for $\mathrm{C}_{12} \mathrm{~A}_{0} \mathrm{G}$ compared with $\mathrm{C}_{12} \mathrm{~A}_{\mathrm{m}} \mathrm{G}$. This concentration can be roughly regarded as a measure of the saturation concentration of the surfactant molecules in lipid bilayer, when the partition coefficients of the surfactants between aqueous phase and lipid membrane are comparable. That is, the higher the concentration is, the more surfactant molecules the lipid bilayer can accommodate without destruction of the bilayer structure. The high saturation concentration of $\mathrm{C}_{12} \mathrm{~A}_{0} \mathrm{G}$ in lipid bilayer means that rather strong interaction is acting between $\mathrm{C}_{12} \mathrm{~A}_{0} \mathrm{G}$ and egg $\mathrm{PC}$ molecules. This strong interaction

Table 3 Contribution of Guanidine-type Surfactants to the Release of CF from Egg Yolk PC Liposome in Mixed Surfactant Solution. The concentrations of NRE and $\mathrm{C}_{12} \mathrm{~A}_{\mathrm{m}} \mathrm{G}$ are 0.01 and $0.002 \mathrm{wt} \%$, respectively. The amount of CF released in NRE solution is $57.9 \%$

\begin{tabular}{ccccc}
\hline & $\begin{array}{c}\text { Mixed concentration } \\
(10-4 \mathrm{M})\end{array}$ & $\begin{array}{c}\text { Release of CF } \\
(\%)\end{array}$ & $\begin{array}{c}\text { Rise in release } \\
(\%)\end{array}$ & $\begin{array}{c}\text { Contribution of mixed } \\
\text { surfactant }(\% 10-4 \mathrm{M})\end{array}$ \\
\hline $\mathrm{C}_{12} \mathrm{~A}_{0} \mathrm{G}$ & 0.76 & 74.5 & 16.6 & 21.8 \\
$\mathrm{C}_{12} \mathrm{~A}_{2} \mathrm{G}$ & 0.62 & 67.7 & 9.7 & 15.6 \\
$\mathrm{C}_{12} \mathrm{~A}_{4} \mathrm{G}$ & 0.57 & 65.3 & 7.4 & 12.9 \\
\hline
\end{tabular}


might again come from hydrogen-bond interaction between guanidine group and head group of PC molecules.

The results of $\mathrm{CF}$ leakage experiments are shown in Table 3. The guanidine-type surfactants affect the CF release from egg-PC liposome induced by NRE, and the effect follows the order $A_{0}>A_{2}>A_{4}$. When the surfactant concentration is low as in the present case, the release of solute molecules entrapped inside the liposome occurs as a result of disturbance of lipid bilayer caused by the surfactant molecules incorporated into the bilayer membrane. In some cases, several surfactant molecules would aggregate in the lipid bilayer to form a path through which the leakage of solute molecules takes place. The large effect of $\mathrm{C}_{12} \mathrm{~A}_{0} \mathrm{G}$ on $\mathrm{NRE}$-induced $\mathrm{CF}$ release compared with $\mathrm{C}_{12} \mathrm{~A}_{2} \mathrm{G}$ and $\mathrm{C}_{12} \mathrm{~A}_{4} \mathrm{G}$ may be caused by the stronger interaction of $\mathrm{C}_{12} \mathrm{~A}_{0} \mathrm{G}$ with egg $\mathrm{PC}$ molecules in lipid bilayer.

\subsection{Molecular structure of guanidine-type surfactants and skin reactions}

Figure 7 shows the results of the guinea pig skin tests for guanidine-type surfactants. Mean skin irritation scores for the guanidine-type surfactants are as follows: $\mathrm{C}_{12} \mathrm{~A}_{6} \mathrm{G} \cong$ $\mathrm{C}_{12} \mathrm{~A}_{4} \mathrm{G}<\mathrm{C}_{12} \mathrm{~A}_{3} \mathrm{G}<\mathrm{C}_{12} \mathrm{~A}_{2} \mathrm{G}<\mathrm{C}_{12} \mathrm{~A}_{0} \mathrm{G}$, showing that skin irritation decreases with increasing $A_{m}$ chain length. The mean skin irritation score for DTAC increases with additional application to reach a maximum mean score of 7.8 (strong irritation), and decreases after the application period finished. Cationic surfactants with $\mathrm{C}_{12}$ chain are primarily physiologically active and have high antibacterial activity ${ }^{21,22}$. The maximum mean score for $\mathrm{C}_{12} \mathrm{~A}_{0} \mathrm{G}$ is higher than or equal to that of DTAC, and it decreases with increasing $A_{m}$ chain length. The lowest maximum mean score is obtained when the value of $m$ is larger than 4. It is possible that the $A_{m}$ group in the guanidine-type surfactants makes the hydrophilic moiety bulkier and weakens the interactions between guanidine group and organised biological substances such as proteins and lipid

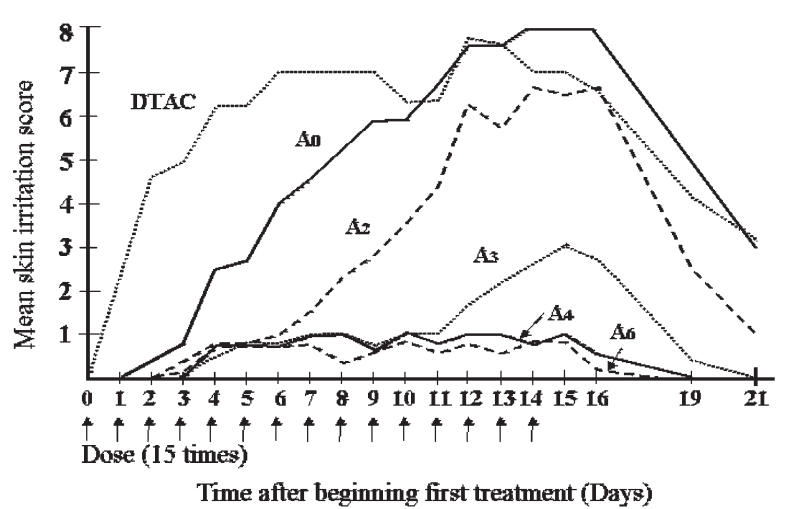

Fig. 7 Skin Irritation Scores of $\mathrm{C}_{12} \mathrm{~A}_{0} \mathrm{G}\left(\mathrm{A}_{0}\right)$ and $\mathrm{C}_{12} \mathrm{~A}_{\mathrm{m}} \mathrm{G}$ $\left(A_{m}\right)$ Determined by the Draize Scoring Method. bilayers. The bulkiness of the $\mathrm{A}_{\mathrm{m}}$ groups with $m$ greater than 4 sufficiently depresses these interactions. In addition, skin irritation caused by guanidine-type surfactants is delayed when compared to DTAC. The mechanism of skin irritation is beyond the scope of this work, and a full discussion would require evaluation of skin permeability. We infer, however, that the mechanism would involve the ability of guanidine groups to induce the aggregation of proteins and lipid bilayers in the corneum.

\section{CONCLUSION}

Skin irritation caused by surfactants involves protein denaturation $^{23,24)}$ and cell membrane disturbance ${ }^{25,26)}$. The strong skin irritating action of $\mathrm{C}_{12} \mathrm{~A}_{0} \mathrm{G}$ would be related to the property that a small number of binding induces the partial destruction of $\alpha$-helical structure in protein molecules as demonstrated for BSA. In addition, $\mathrm{C}_{12} \mathrm{~A}_{0} \mathrm{G}$ induces the aggregation of egg-PC liposome. It is proposed that hydrogen bonding between guanidine group and biological substances contributes to their aggregation. In contrast, the $\mathrm{A}_{4}$ group in $\mathrm{C}_{12} \mathrm{~A}_{4} \mathrm{G}$ reduces the ability of the surfactant to cause the aggregation of proteins and liposomes. The reduced skin irritation resulting from the introduction of $\mathrm{A}_{\mathrm{m}}$ chain may come from the weakened hydrogen-bonding ability of guanidine groups due to the spacer group.

\section{ACKNOWLEDGEMENT}

We express our sincere appreciation to Dr K. Sugiyama, Director and Executive General Manager of Research \& Development Headquarters, Lion co., N. Yamamoto, Director of Functional Materials Research Laboratories, Lion co., and H. Harada, Human \& Environmental Safety Evaluation Center, Lion co., for permission to publish this paper.

\section{References}

1. Yoshida, R.; Takeda, M,; Sakamoto, K. Surfactants derived from amino acids. I. Critical micelle concentrations of the salts of optically active and racemic N-acylamino acids. J. Jpn. Oil Chem. Soc. 24, 538-541 (1975).

2. Sakamoto, K. Application and effect of derivatives of amino acids for hair. Fragrance J. 39, 57-62 (1979).

3. Osanai, S.; Itoh, T.; Yoshikawa S. Synthesis and properties of the substituted guanidine type amphoteric surfactants. J. Jpn. Oil Chem. Soc. 37, 508-513 (1988).

4. Mitamura, J.; Suzuki, N.; Ohonuma, K.; Miyake, M.; Nakamura, T.; Kiyomiya, A. Development of new cationic surfactant "AG" and application for hair condi- 
tioners. J. Soc. Cosmet. Chem. Jpn.. 30, 84-92 (1996).

5. Arai, M.; Sizuiki, T.; Kaneko, Y.; Miyake, M.; Nishikawa, N. Properties of aggregates of amide guanidine type cationic surfactant with 1-hexadecanol adsorbed on hair. Proceedings of Studies in Surface Science and Catalysis 132, International Conference on Colloid and Surface Science. p.132 (2001).

6. Fish, W.W.; Danielsson, A.; Nordling, K.; Miller, S.H.; Lam, C.F.; Bjork, L. Denaturation behaviour of antithrombin in guanidinium chloride. Irreversibility of unfolding by aggregation. Biochemistry 24, 1510-1517 (1985).

7. Sasaki, D.Y.; Krihara, K.; Kunieda, T. Specific multiplepoint binding of ATP and AMP to a guanidinium-functionalized monolayer. J. Am. Chem. Soc. 113 , 96859686 (1991).

8. Morgan, E.W.; Mullen, L.; Korte, D.W. Primary dermal irritation potential to guanidine hydrochloride in rabbits. Report 1986 LAIR-213, Order No. ADA166306/1/GAR, p.24.

9. Srivastava, S.K.; Smith, T.A. The inhibition of growth in higher plants by a homologous series of guanidines and its reversal by spermine. Ann. Bot. 50, 265-275 (1982).

10. Cabral, Joao P.S.; Smith, A.R. Determination of the critical micelle concentration of dodecylguanidine monoacetate. J. Colloid and Interface Sci. 149, 27-33 (1992).

11. Yoshida, R.; Baba, K.; Asitho, T.; Yoshimura, I. Surfactants derived from amino acids. Some surface active properties and antimicrobial activities of salts of long chain N-acyl-L-arginine esters. J. Jpn. Oil Chem. Soc. 25, 404-408 (1976).

12. Miyake, M,; Yamada, K.; Oyama, N. Self-assembling of guanigine-type surfactant. Langmuir 24, 8527-8532 (2008).

13. Miyake, M.; Oyama, N. Effect of amidoalkyl group as spacer on aggregation properties of guanidine-type suefactant. J.Colloid and Interface Sci. 330, 180-185 (2009).

14. Fukui, H.; Hatano, K.; Kamino, K.; Miyake, M.; Tamura, T.; Hayakawa, K. Cooperative binding and the conformation of poly (L-glutamic acid) in guanidinium salts with an alkanoylamidoalkyl group. J. Phys. Chem. B 107, 8218-8222 (2003).

15. Ohbu, K.; Jona, N.; Miyajima, N.; Mizushima, N.; Kashiwa, I. Evaluation of denaturation property of surfactants onto protein as measured by circular dichroism. J. Jpn. Oil Chem. Soc. 29, 866-871 (1980).

16. Draize, J.H. Appraisal of the Safety of Chemicals in Foods, Drugs and Cosmetics. The Association of Food and Drug Officials of the United States. pp.46-59 (1965).

17. Guide to Marketing and Manufacturing of Cosmetics and Quasi-Drugs 2008. Yakuji Nippo Ltd. (2008).

18. Hiramatsu, K.; Ueda, C.; Iwata, K.; Arikawa, K.; Aoki, $\mathrm{K}$. The interaction of bovine plasma albimin with cationic detergent. Studies by binding isotherm, optical rotation and difference spectrum. Bull. Chem. Soc. Jpn. 50, 368-372 (1977).

19. Scatchard, G. The attraction of proteins for small molecules and ions. Ann. N.Y. Acad. Sci. 51, 660-665 (1949).

20. Jones, M.N.; Skinner, H.A.; Tipping, E. The interaction between bovine serum albumin and surfactant. Biochem. J. 147, 229-234 (1975).

21. Nakama,Y.; Yamaguchi, M. Adsorption of cationic surfactants to keratin powder. J. Jpn. Oil Chem. Soc. 41, 336-340 (1992).

22. Harrold, S.P. Denaturation of epidermal keratin by surface active agents. J. Invest. Dermatol. 32, 581-588 (1959).

23. Van Scott, E.J.; Lyon J.B. A chemical measure of the effect of soap and detergents on the skin. J. Invest. Dermatol. 21, 199-203 (1959).

24. Imokawa, G.; Katsumi, E. Denaturing action of typical anionic surfactants on several proteins. J. Jpn. Oil Chem. Soc. 25, 24-30 (1976).

25. Imokawa, G.; Mishima, Y. Cumulative effect of surfactant on cutaneous horny layers. Lysosomal activity of human keratin layer in vivo. Contact Dermatitis 7, 65-71 (1981).

26. Imokawa, G.; Mishima, Y. Cumulative effect of surfactant on cutaneous horny layers. Lysosome labilizing action. Contact Dermatitis 5, 151-162 (1979). 